\title{
Degree of Pulmonary Hypertension in Patients of COPD Attending a Tertiary Care Hospital
}

\author{
Afshan Ali Shaik ${ }^{* 1}$, Durga Lawande ${ }^{2}$ \\ ${ }^{1}$ Senior Resident, ${ }^{2}$ Professor and Head \\ Department of Pulmonary Medicine, Goa Medical College, Taleigao-Goa, India \\ *Corresponding author: Afshan Ali Shaik; afshanshaik68@gmail.com \\ Received 04 April 2021; \\ Accepted 12 May 2021;
}

Published 21 May 2021

\begin{abstract}
Introduction: Chronic obstructive pulmonary disease (COPD) is a major cause of morbidity and mortality in India. The development of pulmonary hypertension (PH) in COPD adversely affects survival and exercise capacity and is associated with an increased risk of severe acute exacerbation. Aims and Objectives: Present study aimed to describe the distribution of echocardiographically assessed pulmonary artery systolic pressure in the COPD patients attending pulmonary medicine OPD, to estimate the proportion of PH among such patients and to identify associated factors. Methodology: This Cross sectional study was done on 145 patients of COPD fulfilling the inclusion criteria were included in this study. These patients were evaluated for the presence of PH using chest X-ray, 2D-Echocrdiography and electrocardiogram. $\underline{\text { Results: }}$ Pulmonary hypertension was present in $17(29.8 \%)$ patients with moderate, $36(60 \%)$ with severe and 18 (72\%) with very severe COPD. Mild PH was seen in 52(73\%), moderate in 11(15.4\%) and severe in 8(11.2\%) patients. Patient exposed to both smoking and biomass fuel smoke had more frequent occurrence of $\mathrm{PH}(56.8 \%)$ as compared to exposure to single risk factor of either tobacco smoke (47.1\%) or biomass fuel (52.4\%). Thus overall proportion of $\mathrm{PH}$ among reported cases of COPD patients was $48.6 \%$ in our study. Conclusion: With the increase in severity of COPD the proportion of PH rises. This study emphasizes the early detection of COPD and the importance of screening for PH through clinical assessment and non- invasive techniques 2-D Echocardiography.
\end{abstract}

Keywords: Chronic obstructive pulmonary disease, pulmonary hypertension, echocardiography.

\section{Introduction}

COPD is the fourth leading cause of death and is projected to be the $3^{\text {rd }}$ leading cause by $2020^{[1]}$. The prevalence of $\mathrm{PH}$ in stable COPD patients varies from $10-30 \%{ }^{[2]}$. PH is defined as a mean pulmonary artery pressure of $\geq 25 \mathrm{mmHg}$ at rest ${ }^{[3,4]}$. The ideal method to diagnose $\mathrm{PH}$ is right heart catherization. However in the absence of this facility, transthoracic Doppler echocardiography is a non- invasive screening test for detection of $\mathrm{PH}$ which fairly correlates the catherization findings.

The development of PH in COPD adversely affects survival and exercise capacity and is associated with an increased risk of severe acute exacerbation; therefore its early detection is mandatory to prevent heart failure ${ }^{[5]}$.

\section{Aims and Objectives}

This study aimed to describe the distribution of echocardiographically assessed pulmonary artery systolic pressure in the COPD patients attending pulmonary medicine OPD, to estimate the proportion of $\mathrm{PH}$ among such patients and to identify associated factors.

\section{Methodology}

145 patients of COPD proven by spirometry as per latest GOLD Guidelines ${ }^{[6]}$ attending the outpatient department of pulmonary medicine, were evaluated for presence of $\mathrm{PH}$ using chest X-ray, 2D-Echocardiography and electrocardiogram.

We included patients with age more than 40 years and with history of smoking with pack years of more than 20 and /or exposure to biomass fuel smoke. A significant biomass exposure was defined as a subject with more than 80 hours/year with a minimum exposure of 10 years. For patients with dual exposure of biomass and smoking, biomass fuel smoke exposure of $\geq 80$ hours/years with a minimum exposure of 10 years with a pack years of $\geq 20$ is considered significant dual exposure.

We excluded patients below 40 years of age, patients with other pulmonary diseases like tuberculosis, bronchiectasis, interstitial pulmonary disease and bronchial asthma, patients with unstable cardio respiratory status defined as occurrence of respiratory failure, broncho pulmonary infection or congestive cardiac failure in previous two months, structural diseases of heart e.g. valvular heart disease, congenital heart disease and cardiomyopathy, ischemic heart disease like typical angina pectoris 
or prior myocardial infarction,patients with primary pulmonary hypertension and hepatic and renal insufficiency.

The parameters noted on echocardiography with the use of 2-D, Color Doppler and $\mathrm{M}$ mode were size of right atrium and ventricle, Grade of $\mathrm{PH}$, presence or absence of tricuspid regurgitation signifying severity of $\mathrm{PH}$ and pulmonary artery pressure estimation

Pulmonary artery pressure was estimated based on peak tricuspid regurgitation velocity (TRV) and right atrial pressure (RAP) as per Bernoulli Equation

Pulmonary artery pressure $=$ Right Ventricular Systolic Pressure (RVSP)

$\mathrm{RVSP}=4 \mathrm{v}^{2}+\mathrm{RAP}$
$\mathrm{V}=$ tricuspid regurgitant velocity, $\mathrm{RAP}=$ Right atrial pressure

Right atrial pressure was estimated based on the diameter and respiratory variation in diameter of the inferior vena cava (IVC) ${ }^{[7]}$. A normal RA pressure of $3 \mathrm{mmHg}$ (normal range of $0-5 \mathrm{mmHg}$ ) is when IVC diameter is $<2.1 \mathrm{~cm}$ that collapses $>50 \%$. High RA pressure of $15 \mathrm{mmHg}$ (normal range $10-20 \mathrm{mmHg}$ ) is suggested when IVC is $<20 \%$ collapsible. An intermediate value of $8 \mathrm{mmHg}$ is used when IVC diameter and collapsibility does not fit the above mentioned values.

Echocardiographic probability of pulmonary hypertension in symptomatic patients as per Lang RM et al is shown in table 1 [8].

Table: 1

\begin{tabular}{|l|l|l|}
\hline Peak tricuspid regurgitation velocity $(\mathrm{m} / \mathrm{s})$ & Presence of other echo PH signs & Echocardiographic probability of pulmonary hypertension \\
\hline $2.9-3.4$ & Yes & High \\
$>3.4$ & Not required & \\
\hline$\leq 2.8$ or not measurable & Yes & Intermediate \\
$2.9-3.4$ & No & \\
\hline$\leq 2.8$ or not measurable & No & Low \\
\hline
\end{tabular}

Grading of PH was done according to American heart association guidelines ${ }^{[9]}$. 36-50mmHg was considered as mild, 51-60 mmHg was considered as moderate and $>60 \mathrm{mmHg}$ was considered as severe

\section{Results}

Out of 145 subjects included in our study, the variables which were observed are listed in table 2

Table 2

\begin{tabular}{|l|c|c|}
\hline Variables studied & $\begin{array}{c}\text { No of cases } \\
\text { n }\end{array}$ & \% \\
\hline Male & 76 & $53 \%$ \\
\hline Female & 22 & $47 \%$ \\
\hline Age group 40-55yrs & 77 & $15 \%$ \\
\hline Age group 56-70 yrs & 46 & $32 \%$ \\
\hline Age group 70 yrs & 104 & $72 \%$ \\
\hline Tobacco smokers & 42 & $28 \%$ \\
\hline Biomass fuel smoke exposure & 37 & $25 \%$ \\
\hline Dual exposure to tobacco and biomass smoke & 37 \\
\hline
\end{tabular}

Table 3: The association between pulmonary hypertension and severity of COPD

\begin{tabular}{|l|l|l|l|l|}
\hline Severity of COPD & Presence of PH( $\mathbf{n})$ & Total number of cases $(\mathbf{N})$ & \% & 'p 'value \\
\hline Mild COPD & 0 & 3 & $0 \%$ & 0.078 \\
\hline Moderate COPD & 17 & 57 & $29.8 \%$ & $<0.001$ \\
\hline Severe COPD & 36 & 60 & $60 \%$ & 0.022 \\
\hline Very severe COPD & 25 & $72 \%$ & 0.017 \\
\hline
\end{tabular}

It was observed that as severity of COPD increased the proportion of cases with pulmonary hypertension also increased. These findings were statistically significant as shown in table 3 ( $\mathrm{p}$ value $<0.05$ ).

Table 4: The association between grades of COPD and severity of pulmonary hypertension

\begin{tabular}{|l|l|l|l|l|}
\hline Severity of COPD & $\begin{array}{l}\text { Mild PH } \\
\mathbf{n} / \text { total no of COPD cases } \\
(\mathbf{n} \%)\end{array}$ & $\begin{array}{l}\text { Moderate PH } \\
\mathbf{n} / \text { total no of cases } \\
(\mathbf{n \%})\end{array}$ & $\begin{array}{l}\text { Severe PH } \\
\mathbf{n} / \text { total no of cases } \\
(\mathbf{n} \%)\end{array}$ & ' $\mathbf{p}$ ' value \\
\hline Moderate COPD & $14 / 57$ & $2 / 57$ & $1 / 57$ & $<0.001$ \\
& $(24 \%)$ & $(3 \%)$ & $4.7 \%)$ & \\
\hline Severe COPD & $31 / 60$ & $1 / 60$ & $4 / 60$ \\
$(1.6 \%)$ & $8 / 25$ & $3 / 25$ \\
\hline Very Severe COPD & $(51.6 \%)$ & $(32 \%)$ & $8 \%)$ & \\
\hline Total no of cases of PH & $7 / 25$ & 11 & 8 & \\
\hline
\end{tabular}


Most of the moderate to severe COPD cases had mild degree of PH, whereas most of the patients with very severe COPD had moderate degree of PH. It was thus observed that severity of pulmonary hypertension increased with increasing severity of COPD, which was statistically significant $(<\mathrm{p}$ value 0.001$)$ as shown in table 4 .

Table 5: The Association between risk factors and pulmonary hypertension

\begin{tabular}{|l|c|c|c|c|}
\hline Risk factors & $\begin{array}{c}\text { PH present } \\
\text { (n) }\end{array}$ & $\begin{array}{c}\text { Total number of } \\
\text { cases (N) }\end{array}$ & \% 'P' value \\
\hline Biomass fuel smoke exposure & 22 & 42 & $52.4 \%$ & 0.564 \\
\hline Tobacco Smoker & 49 & 104 & $47.1 \%$ & 0.564 \\
\hline Combined Smokers and biomass fuel smoke exposure & 21 & 37 & $56.8 \%$ & 0.252 \\
\hline
\end{tabular}

It was observed that patients having dual exposure to smoking and biomass fuel had more incidence of pulmonary hypertension (56.8\%) as compared to single risk factor of either biomass fuel (52.4\%) or tobacco smoking (47.1\%) alone. However these results were statistically not significant.

\section{Discussion}

Pulmonary Hypertension (PH) is defined as an increase in mean pulmonary arterial pressure (PAPm) is $\geq 25 \mathrm{mmHg}$ at rest assessed by right heart catherization (RHC) ${ }^{[2]}$. PH in COPD affects survival and exercise capacity and is associated with increased risk of acute exacerbation. The pulmonary pressure increases during exercise, REM sleep and exacerbations which, eventually leads to right heart failure

In present study, out of 145 patients, $3(0.2 \%)$ had mild, 57 (39\%) had moderate, $60(41.3 \%)$ had severe and $25(17 \%)$ had very severe COPD. Pulmonary hypertension was present in $17(29.8 \%)$ patients with moderate, 36(60\%) with severe and 18(72\%) with very severe COPD patients. Pulmonary hypertension was not seen in our patients with mild COPD. Thus overall prevalence of $\mathrm{PH}$ among reported cases of COPD patients in our study was $48.6 \%$. These results were statistically significant ( $\mathrm{p}$ value $<0.05$ ). A similar study done by Shruthi Reddy et $\mathrm{al}^{[10]}$ found that the prevalence of $\mathrm{PH}$ among COPD patient was $50 \%$. In a study by Gupta NK et $\mathrm{al}^{[11]}$, the prevalence of $\mathrm{PH}$ in mild, moderate and very severe COPD were $16.67 \%, 54.55 \%, 60 \%$ and $83.33 \%$. Approximately $25 \%$ patients with COPD eventually develop cor pulmonale ${ }^{[12]}$.

Out of 71 total cases of PH, we had 52(73\%) cases with mild,11(15.4\%) with moderate and 8 (11.2\%)with severe PH. A similar study done observed mild $\mathrm{PH}$ in $50.2 \%$, moderate in $9.8 \%$, severe in $3.7 \%$ cases of COPD ${ }^{[13]}$. Hyperinflation in COPD, compresses the alveolar vessels resulting in pulmonary vasoconstriction, destruction of vascular bed, vascular remodeling and polycythemia thus increasing the pulmonary vascular resistance, ultimately resulting in the development of $\mathrm{PH}^{[14]}$. Thus the incidence of PH is directly proportional to severity of airflow limitation.

As per the smoking status our keen observation was that patients exposed to both smoking and biomass fuel smoke had more frequent occurrence of $\mathrm{PH}(56.8 \%)$ as compared to exposure to single risk factor of either tobacco smoke $(47.1 \%)$ or biomass fuel $(52.4 \%)$. However these results were statistically not significant. Biomass is composed of mixture of gases and particles that penetrate deeply into the lung and cause morphologic and biochemical changes and are risk factors for COPD ${ }^{[15,16]}$. In a study by Rivera et al vascular changes were prominent in both groups, but more severe in the biomass exposed group which could explain why pulmonary hypertension is seen more in biomass exposed group ${ }^{[17]}$. The pathophysiology of the development of $\mathrm{PH}$ in COPD patients is due to chronic exposure of airways to noxious particles like tobacco smoke and biomass fuel smoke. Hence combined exposure to smoking and biomass increases the risk of PH. A similar study done by bunyamin et al showed that frequency of $\mathrm{PH}$ is higher in patients exposed to biomass fuel than tobacco smoke ${ }^{[18]}$.

\section{Conclusion}

Pulmonary Hypertension is one of the most common complication of COPD. COPD associated PH is recognized as a poor prognostic marker. It is associated with increased risk of exacerbation, worsened exercise capacity, poor oxygenation and increased mortality. As severity of COPD increases the proportion of cases with increased severity of $\mathrm{PH}$ increases. Severe $\mathrm{PH}$ increases the right ventricular afterload and eventually leads to heart failure. This study emphasizes the early screening of patients of COPD for $\mathrm{PH}$ through clinical assessment and non invasive testing like 2-D Echocardiography.

\section{Funding}

No funding sources

\section{Conflict of interest}

None

\section{Acknowledgement}

I would like to thank Dr Manjunath Desai, Associate Professor, Department of Cardiology for assisting us with echocardiographic study

\section{References}

[1] Lozano R, Naghavi M, Foreman K, et al. Global and regional mortality from 235 causes of death for 20 age group in 1990 and 2010; a systematic analysis for the Global Burden of Disease Study 2010. Lancet.2012; 380(9859): 2095-128.

[2] Naeije R, MacNee W, Calverley P, et al. Chronic obstructive pulmonary disease, $2^{\text {nd }}$ edition. London. Arnold Heath Sciences. 2003:228-242.

[3] Galie N, Hoeper MM, Humbert M, et al. Guidelines for the diagnosis and treatment of pulmonary hypertension: the Task Force for the Diagnosis and Treatment of Pulmonary Hypertension of the European Society of Cardiology (ESC) and the European Respiratory Society (ERS), endorsed by the International Society of Heart and Lung Transplantation (ISHLT). Eur Respir J. 2009; 34(6):1219-63. 
[4] McLaughlin VV, Archer SL, Badesch DB, et al. ACCF/AHA 2009 expert consensus document on pulmonary hypertension" A report of the American College of Cardiology Foundation Task Force on Expert Consensus Documents and the American Heart Association developed in collaboration with the American College of Chest Physicians, American Thoracic Society and the Pulmonary Hypertension Association. J Am Coll Cardiol. 2009; 53(17):1573-619.

[5] Thomas L Petty. The history of COPD. Int J COPD. 2006;1(1):3-14.

[6] Global initiative for Chronic Obstructive Lung Disease Strategy for the Diagnosis, Management and Prevention of Chronic Obstructive Pulmonary Disease Updated 2019, available online at www.goldcopd.org.com

[7] Fisher MR,Forfia PR, Chamera E, et al. Accuracy of Doppler Echocardiography in the hemodynamic assessment of pulmonary hypertension. Am J Respir Crit Care Med.2009; 179(7):615-621.

[8] Lang RM, Badano LP, Mor-Avi V, et al. Recommendations for cardiac chamber quantification by echocardiography in adults: An update from the American Society of Echocardiography and the European Association of Cardiovascular Imaging. Eur Heart $J$ Cardiovasc Imaging. 2015;16(3):233-271.

[9] 2015 ERS/ERS Guidelines for the Diagnosis and treatment of Pulmonary Hyperetension.Eur heart J.2015.

[10] Shruthi Reddy, Rajender and Nihin Reddy. Prevalence of Pulmonary Hypertension in COPD patients; A retrospective observational study. Int journal of integrative Medical Science.2016; 3(5):285-2.

[11] Gupta NK,Agrawal RK, Srivastav AB et al. Echocardiographic evaluation of heart in chronic obstructive pulmonary disease patient and its correlation with severity of disease. Lung India.2011; 28:105-9.

[12] J.L. Wright, L. Lawson, P.D. Pare et al. The structure and function of the pulmonary vasculature in mild COPD. The effect of oxygen and exercise. The American Review of Respiratory disease. 1983;128(4) :702-707.

[13] Thabut G, Dauriat G,Stern JB et al. Pulmonary hemodynamics in advanced COPD candidates for lung volume reduction surgery or lung transplantation. Chest. 2005;127(5):1531-1536.

[14] Fishman AP.State of the art: chronic cor pulmonale. Am Rev Respir Dis. 1976; 114(4):775-94.

[15] Zelikoff JT, Chin Chen L, Cohen MD et al. The toxicology of inhaled wood smoke. $J$ toxicology Environment Health B crit Rev.2002; 5(3):269-282.

[16] $\mathrm{Hu}$ G, Zhou Y, Tian J et al. Risk of COPD from exposure to biomass smoke: A metaanalysis.Chest.2010;138(1):20-31.

[17] Rivera RM, Cosio MG, Ghezzo $\mathrm{H}$ et al. Comparison of lung morphology secondary to cigarette and biomass smoke. Int J Tuberc Lung Dis. 2008;12(8):972-7.

[18] Medhat Soliman, Hussen Heshmat, Yousif Amen et al. Detection of right sided heart changes and pulmonary hypertension in COPD patients. Egyptian Journal of Chest diseases and Tuberculosis.2015;64(2): 335-341. 